\title{
Diagnosis and management of posttraumatic oculorrhea
}

\author{
Khalil Salame, M.D., Yoram Segev, M.D., Dan M. Fliss, M.D., \\ AND GEORGES E. OUAKNINE, M.D. \\ Departments of Neurosurgery, Radiology, and Otolaryngology, Sourasky Medical Center, Sackler, \\ School of Medicine, Tel Aviv University, Tel Aviv, Israel
}

\begin{abstract}
Posttraumatic cranio-orbital cerebrospinal fluid (CSF) fistula is very rare. Diagnosis of these fistulas may be difficult, and it is possible that this complication of craniofacial injury is underdiagnosed. Early recognition and adequate treatment is of paramount importance to prevent hazardous complications. The authors report the case of a 20-yearold woman in whom a CSF leak developed through the medial canthus area of her eye after she sustained a mild sportsrelated injury. Clinical examination and chemical analysis of the fluid led to the correct diagnosis, and the leak was stopped with conservative treatment. It is proposed that a CSF leak through the eye be termed "oculorrhea" as compared with otorrhea and rhinorrhea. The mechanism of the fistula in this patient is discussed, as is the pertinent radiologically demonstrated anatomy and the mechanism of injury. Management and controversies are also discussed.
\end{abstract}

KEY WORDS • cerebrospinal fluid fistula • head injury • oculorrhea • fracture

Cerebrospinal fluid fistulas are well-recognized complications of craniocerebral injury. These fistulas occur in 2 to $3 \%$ of craniocerebral injury cases ${ }^{2}$ and usually manifest as rhinorrhea or otorrhea. Leakage of CSF into the orbit or through the orbit to the exterior ("oculorrhea") may appear when there is communication between the orbital and subarachnoid compartments. This communication may be caused by invasive orbital tumors with intracranial extension into the subarachnoid space ${ }^{6}$ or may develop following orbital surgery if bone removal is extended to the cribriform plate., ${ }^{922}$ Traumatic CSF leakage through the orbit is very rare, and fewer than 20 cases have been reported in the English-language literature. Recently we treated a young patient who developed oculorrhea after sustaining a mild craniofacial injury. This report, the first, we believe, on a cranio-orbital fistula that developed following a sports-related injury, serves also to call attention of trauma surgeons to this rare sequela of head injury.

\section{CASE REPORT}

Presentation. This 20-year-old woman was struck in the face by the sharp edge of a surfing board while swimming in the sea. She lost consciousness for a few moments. Previous history was remarkable only for deviation of the nasal septum.

Examination. On examination in the emergency room

Abbreviation used in this manuscript: CSF = cerebrospinal fluid. she was conscious and oriented. There was left-sided periorbital swelling and ecchymosis (raccoon eye), with slight leakage of clear fluid from the medial canthus area that was thought to be tears. The upper eyelid and conjunctiva were lacerated at the medial canthus. There were no exophthalmus, enophthalmus, rim defects, subcutaneous emphysema, pulsations over the orbit, or bruits. The leftsided pupil was mydriatic but reactive. Eye movements were normal, and there was no evidence of diplopia. The cornea, sclera, and lens were intact; the fundus and macula were normal. Visual acuity was 20/20 in both eyes. There was no rhinorrhea, epistaxis, anosmia, or postnasal drip. The remainder of the neurological and general physical examination was unremarkable.

Computerized tomography scanning (Fig. 1) revealed a depressed fracture of the medial wall of the left orbit with herniation of orbital fat into the ethmoid air cells, a small bone fragment in the soft tissue near the medial canthus, and a fracture of the anterior part of the cribriform plate with pneumocephalus. Intracranial hemorrhage, brain contusion, or edema were not demonstrated.

Operation. The patient underwent ophthalmological surgery after receiving a local anesthetic. The medial wall of the orbit and medial canthus area were explored, a free bone fragment was extracted from the adjacent soft tissue on the medial side of the orbit, the defect in the medial orbital wall was filled with silicone, and reconstruction of the lacerated conjunctiva and upper eyelid was performed. The retina and macula were inspected and found to be normal. 


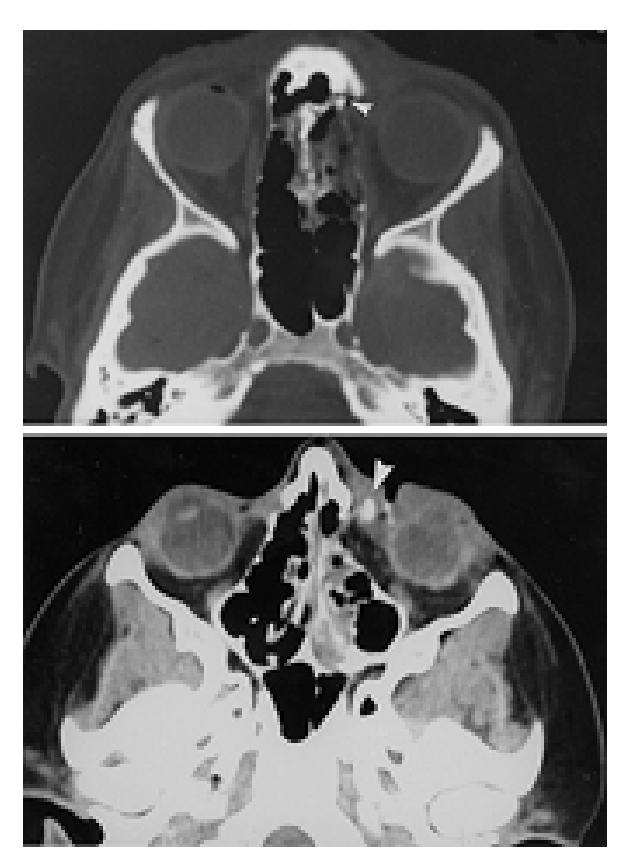

Fig. 1. Axial computerized tomography scans of the orbits. Upper: Bone window CT scan revealing a depressed fracture at the medial orbital wall with herniation of orbital fat into the ethmoidal air cells. The fracture extends to the anterior part of the cribriform plate (arrowhead). Lower: Computerized tomography scan obtained through the soft-tissue window demonstrating a free bone fragment near the medial canthus (arrowhead). Pneumocephalus was observed on higher slices.

Postoperative Course. Several hours after surgery, the fluid leak from the eye became more prominent than before surgery. An ophthalmological consultant ruled out lacrimal outflow obstruction or any other damage to the lacrimal system. Laboratory analysis of the fluid leaking from the eye showed a glucose level of $64 \mathrm{mg} / \mathrm{dl}$; there were no cells, and results of gram stain was negative. The patient was treated conservatively with bed rest, elevation of the head to $30^{\circ}$, continuous lumbar drainage, analgesic medication, and stool softeners. Prophylactic intravenous cefazolin was administered for 24 hours because of the open laceration. The leak stopped after few hours; the lumbar drain was removed after 4 days. Because the leak was halted by conservative treatment, surgery was not planned, and specific studies to localize the fistula were not performed. On discharge 8 days postinjury, the leak had resolved, and there was no CSF rhinorrhea or postnasal drip including during coughing or straining. In the last follow-up visit 16 months after the injury the patient was asymptomatic except for mild enophthalmus.

\section{DISCUSSION}

The brain is normally isolated from the exterior by an anatomical barrier that basically consists of the skin or mucosa of the air sinuses, the periosteum, the skull bones, the dura mater, and the arachnoid membrane. Fistulas may develop when a defect is formed in this barrier. This typically occurs at four anatomical locations: the frontal sinus, the cribriform plate and ethmoid roof, the sphenoid sinus, and the petrous bone. ${ }^{20}$ Cranio-orbital fistulas may rarely occur after orbital surgery in which bone is also removed at the skull base or in cases with invasive orbital tumors that penetrate into the subarachnoid space.

Traumatic cranio-orbital fistulas are very rare, and posttraumatic tearing is more common. It is possible, howev$\mathrm{er}$, that in some of these cases the "tearing" is actually a CSF oculorrhea. Oculorrhea may develop after blunt ${ }^{26}$ or penetrating ${ }^{8}$ injury, but most reported cases have occurred after direct orbital trauma. ${ }^{21}$ The most common injury is a motor vehicle accident, although cases have been described after falls ${ }^{27}$ and assault. ${ }^{13}$

With fractures of the anterior skull base associated with dural tears, the CSF usually leaks through the defect in the dura and the fracture at the cribriform plate and then into the paranasal sinuses and nasal cavity to manifest as rhinorrhea. This route of the CSF leak may be attributed to anatomical-physiological reasons. ${ }^{23}$ Anatomically, the bony walls of the air sinuses are thinner and weaker than the orbital walls and are more frequently fractured. The cribrifrom plate is actually on the roof of the ethmoid sinus, and the distance between the nasal osteum and the skull base is approximately $5 \mathrm{~mm}$. When a fracture involving these structures is associated with dural tears, the route for CSF leak is open. Physiologically, the gradient between the pressure in the subarachnoid space (the intracranial pressure) and the pressure in the air sinuses is significantly higher than between the intracranial pressure and the intraorbital or intraocular pressure. ${ }^{4}$

Cranio-orbital injury with severe breakage of the anatomical barrier between the two compartments may result in hernation of arachnoid membrane ${ }^{25}$ or even brain tissue (that is, encephalocele), into the orbit. ${ }^{10,17}$ In most of the cases, however, the defect allows only CSF leakage. Few authors have reported on cranio-orbital fistulas in which the CSF has remained entrapped within the orbit as orbitocele $^{25}$ or in the soft tissues of the eyelid (blepharocele). ${ }^{11,12,25}$ The differential diagnosis of these orbital masses should include retrobulbar hematoma, orbital abscess, mucocele, or foreign body cyst. ${ }^{14,30}$ In patients with pulsating exophthalmus and local bruit, especially in the presence of ecchymosis, which is common after direct or penetrating orbital injury, cerebral angiography should be performed to exclude the possibility of a carotid-cavernous fistula. ${ }^{16}$

Cranio-orbital fistuals may also manifest with fluid leakage through the orbit to the exterior. A case of profuse CSF drainage through the orbit following avulsion of the eye was documented by Walsh and Hoyt. ${ }^{29}$ Other cases of CSF leakage that initially appeared as tears, as in our patient, have also been described. ${ }^{16,27}$ Whereas other authors ${ }^{11}$ used the term "pseudoepiphora," we suggest that CSF leakage through the orbit be termed oculorrhea, as compared with the terms rhinorrhea and otorrhea.

The diagnosis of CSF oculorrhea may be difficult. Dryden and Wulc ${ }^{10}$ have reported the case of a 2 -year-old child in whom a CSF leak developed through the orbit after being injured in a motor vehicle accident. Unilateral leakage through the orbit was evident immediately after the injury. Obstruction of lacrimal duct outflow was diagnosed, and the child underwent dacryocystorhinostomy. Correct diagnosis of CSF leak through the orbit was made only 2 years later when persistence of the leak resulted in meningitis. 
Surgeons should suspect CSF oculorrhea in patients with fractures of the anterior skull base extending to the orbital roof or orbital walls, especially following penetrating injury. Oculorrhea must be differentiated from posttraumatic epiphora due to lacrimal duct outflow obstruction. Any patient who presents with excessive posttraumatic drainage through the orbit or excessive "tearing" should be suspected to have CSF oculorrhea. When concomitant rhinorrhea is also observed, the diagnosis may be easier. ${ }^{16}$ Analysis of the fluid for glucose concentration is very helpful. Normally, the glucose level in the CSF is approximately two-thirds the level in the serum whereas glucose concentration in tears is insignificant $(2.5-4.1 \mathrm{mg} / \mathrm{dl}){ }^{13,28} \mathrm{~A}$ glucose level of $30 \mathrm{mg} / \mathrm{dl}$ or higher is diagnostic for such lesions. The glucose level in the drained fluid may also be compared with that in tears from the other eye. Immunoassay for $\beta 2$-transferrin is more specific and requires only a small amount of fluid $(<1$ $\mathrm{ml}$ ). This protein is absent in tears and nasal secretions but is found in significant levels in the CSF. ${ }^{24}$

The route of the CSF leak in CSF oculorrhea is usually through a dural tear, through a fracture in the skull base, and then through a fracture in the orbital roof or orbital walls. ${ }^{10,16,27}$ Galzio, et al., ${ }^{11}$ have described a case of a craniopalpebral fistula that occurred in a patient with unilateral agenesis of a frontal sinus after sustaining a fracture of the anterior part of the orbital roof due to blunt trauma. These authors hypothesized that absence of the frontal sinus allowed direct egress of CSF to the upper lid. Other authors have reported on CSF leakage to the orbit through the superior orbital fissure. ${ }^{1,15}$ Cisternography with iopamidol followed by thin-sectioned coronal-view CT scanning through the bone window is the best method for localization of the fistula, ${ }^{7}$ although radionuclide cisternography remains a reliable method. ${ }^{18}$ The exact localization of the site of leak is imperative, however, only if surgical repair is intended.

That the CSF leaked through the orbit and not the nose in our patient may be explained by the mechanism and morphology of the fracture. The fracture involved continuously the anterior cribriform plate and the medial orbital wall, thus opening a pathway for CSF from the subarachnoid space into the orbit. On the other hand, marked depression of the medial orbital wall and herniated fat tissue blocked the more common route of the CSF leak to the nasal cavity. This rare fracture configuration may be explained by the direct impact to the anterior part of the medial orbital wall. This mechanism is in contrast to the more common mechanism of the medial blow-out fracture, which is caused by a blow to the eyeball with indirect impact to the bony orbital wall and does not involve the skull base.

Of interest is the increase in the volume of the CSF leak after the ophthalmic surgery in our patient. We think that bone fragments that were stuck in the soft tissues at the medial orbital wall partly blocked the route for CSF flow into the orbit. Removal of these bony fragments allowed the CSF leak through the orbit to increase.

The management of CSF fistulas remains controversial. Some authors recommend surgical treatment for all cases to prevent early- or late-onset infection of the central nervous system. ${ }^{5,19}$ Other authors have advocated nonoperative treatment because the majority of these fistulas heal when conservative measures are undertaken. The closure rate has been approximately $85 \%$ with bed rest alone and approximately 95 to $100 \%$ with spinal drainage. ${ }^{2,3}$ Similar controversy exists in the management of posttraumatic orbital CSF leaks, and favorable results have been reported with both conservative treatment ${ }^{11,25}$ and surgical repair. ${ }^{16,27}$ Conservative treatment is unlikely to succeed in the presence of extensive comminuted or displaced skull base fractures associated with large dural tears or persistent intracranial hypertension. ${ }^{20}$ It might also be argued that the chance for spontaneous healing in penetrating injury-induced fistulas is less likely than those due to closed injury, although this issue has not been addressed in the literature. Surgical repair is indicated if conservative treatment fails, as indicated by persistent leakage or worsening pneumocephalus and for delayed-onset fistulas.

\section{CONCLUSION}

In conclusion, craniofacial injury with fractures involving the orbit and the skull base may develop CSF leakage through the orbit (oculorrhea). Most of the cases of posttraumatic oculorrhea have been reported in children or young adults. Patients usually present with different ophthalmological findings and some of them also present with rhinorrhea. Careful radiological assessment for fractures in the orbital roof or walls and accurate knowledge of the anatomical relationships allow early diagnosis and adequate treatment.

\section{References}

1. Bagolini B: Leakage of spinal fluid into upper eyelid following trauma. Arch Ophthalmol 71:332-343, 1964

2. Bergman TA, Rockswold GL: Cerebrospinal fluid fistulae, in Youmans JR, (ed): Neurological Surgery, ed 4. Philadelphia: WB Saunders, 1996, pp 1840-1852

3. Brawley BW, Kelly WA: Treatment of basal skull fractures with and without cerebrospinal fluid fistulae. J Neurosurg 26: 57-61, 1967

4. Caldicott WJH, North JB, Simpson DA: Traumatic cerebrospinal fluid fistulas in children. Neurosurgery 38:1-9, 1973

5. Calvert CA, Cairns H: Discussion on injuries of the frontal and ethmoidal sinuses. Proc R Soc Med 35:805-810, 1942

6. Carey PC: Epidermoid and dermoid tumors of the orbit. $\mathbf{B r} \mathbf{J}$ Ophthalmol 42:225-239, 1958

7. Colquhoun IR: CT cisternography in the investigation of cerebrospinal fluid rhinorrhoea. Clin Radiol 47:403-408, 1993

8. Cooper AC: Orbito-cranial stab wounds. Ophthalmologica 134: $366-372,1957$

9. de Conciliis C, Bonavolonta G: Incidence and treatment of dural exposure and CSF leak during orbital exenteration. Ophthal Plast Reconstr Surg 3:61-64, 1987

10. Dryden RM, Wulc AE: Pseudoepiphora from cerebrospinal fluid leak: case report. Br J Ophthalmol 70:570-574, 1986

11. Galzio RJ, Lucantoni D, Zinobii M, et al: Traumatic craniopalpebral cerebrospinal fluid fistula. J Neurosurg Sci 25: 105-107, 1981

12. Garza-Mercado R, Aragon-Lomas J, Martinez-Garza J, et al: Cerebrospinal fluid blepharocele: an unusual complication of head injuries. Neurosurgery 11:525-526, 1982

13. Giardini A, Roberts JRE: Concentration of glucose and total chloride in tears. Br J Ophthalmol 34:737, 1950

14. Harris GJ: Subperiosteal abscess of the orbit. Arch Ophthalmol 101:751-757, 1983 
15. Ide $\mathrm{CH}$, Webb RW: Penetrating transorbital injury with cerebrospinal orbitorrhea. Am J Ophthalmol 71:1037-1039, 1971

16. Joshi KK, Crockard HA: Traumatic cerebrospinal fluid fistula simulating tears. Case report. J Neurosurg 49:121-123, 1978

17. King AB: Traumatic encephalocele of the orbit. Arch Ophthalmol 46:49-56, 1951

18. Kirchner FR, Proud GO: Method of identification and localization of cerebrospinal fluid rhinorrhea and otorrhea. Laryngoscope 70:921-923, 1960

19. Lewin W: Cerebrospinal fluid rhinorrhea in nonmissile head injuries. Clin Neurosurg 12:237-252, 1964

20. McCormack B, Cooper PR: Traumatic cerebrospinal fluid fistulas, in Narayan RJ, Wilberger JE, Povlishock JT (eds): Neurotrauma. New York: McGraw-Hill, 1996, pp 639-653

21. Morgan BDG, Madan DK, Bergerot JPC: Fractures of the middle third of the face- - a review of 300 cases. Br J Plast Surg 25:147-151, 1972

22. Neuhaus RW, Baylis HI: Cerebrospinal fluid leakage after dacryocystorhinostomy. Ophthalmology 90:1091-1095, 1983

23. Ritleng P, Caubet E, Fantin J: [Lacrimo-meningeal relations: anatomical study and practical aspects.] Bull Soc Ophthalmol Fr 84:1205-1208, 1984 (Fr)

24. Ryall RG, Peacock MK, Simpson DA: Usefulness of $\beta_{2}$-transferrin assay in the detection of cerebrospinal fluid leaks following head injury. J Neurosurg 77:737-739, 1992
25. Sibony PA, Anand AK, Keuskamp PA, et al: Posttraumatic cerebrospinal fluid cyst of the orbit. Case report. J Neurosurg 62: 922-924, 1985

26. Smith RR, Blount RL: Blowout fracture of the orbital roof with pulsating exophthalmus, blepharoptosis, and superior gaze paresis. Am J Ophthalmol 71:1052-1054, 1971

27. Till JS, Marion JR: Cerebrospinal fluid masquerading as tears. South Med J 80:639-640, 1987

28. Van Haeringen JH: Clinical biochemistry of tears, in Milder B, Weil B (eds): The Lacrimal System. Norwalk, CT: AppletonCentury Crofts, 1983, pp 23-48

29. Walsh FB, Hoyt WF: Clinical Neuroophthalmology, ed 3. Baltimore: Williams \& Wilkins, 1969, pp 551-566

30. Wolter JR, Vanderveen GJ, Wacksman RL: Posttraumatic subgaleal hematoma extending into the orbit as a cause of permanent blindness. J Pediatr Ophthalmol Strabismus 15: $151-153,1978$

Manuscript received May 15, 2000.

Accepted in final form June 19, 2000.

Address reprint requests to: Khalil Salame, M.D., Department of Neurosurgery, Sourasky Medical Center, 6 Weizmann st., Tel Aviv, Israel 64239. email: salame @ tasmc.health.gov.il. 